\title{
Dietary fish oil increases IL-4 secretion by murine splenocytes by an effect on accessory cells
}

\author{
D. H. Petursdottir and I. Hardardottir \\ Department of Biochemistry and Molecular Biology, Faculty of Medicine, University of Iceland, 101 Reykjavik, Iceland
}

Dietary fish oil has immunomodulatory effects ${ }^{(1)}$. It decreases T-cell proliferation, reduces macrophage eicosanoid synthesis and has different effects on cytokine secretion by T-cells and macrophages. The present study examined the effects of dietary fish oil on secretion of T-helper (Th) 1 and Th2 type cytokines by splenocytes and the involvement of accessory cells in the effects of dietary fish oil on cytokine secretion.

Mice were fed diets supplemented with $(\mathrm{g} / \mathrm{kg}) 180$ fish oil +20 maize oil or 200 maize oil for 6 weeks $(n$ 10). Spleen cells, isolated T-cells, and splenocytes depleted of T-cells were stimulated with concanavalin A (ConA), anti-CD3 or anti-CD3/anti-CD28. Secretion of the Th1 and Th2 cytokines interferon- $\gamma$ (IFN- $\gamma$ ) and IL-4 and the pro- and anti-inflammatory cytokines TNF $\alpha$ and IL-10 were measured by ELISA.

Dietary fish oil decreased ConA-, anti-CD3-, and anti-CD3/anti-CD28-induced secretion of IFN- $\gamma$ and TNF $\alpha$ by total splenocytes and isolated T-cells $(P<0.05)$. On the other hand, dietary fish oil increased secretion of IL-4 by total splenocytes $(P<0.05)$ without an effect on IL-4 secretion by isolated T-cells (Figure). When isolated T-cells were cultured with CD11b + cells, T-cells from mice fed the fish oil diet secreted more IL-4 than T-cells from mice fed the maize oil diet $(P<0.05$; Figure).

\section{IL-4 secretion following stimulation \\ with anti-CD3/anti-CD28}

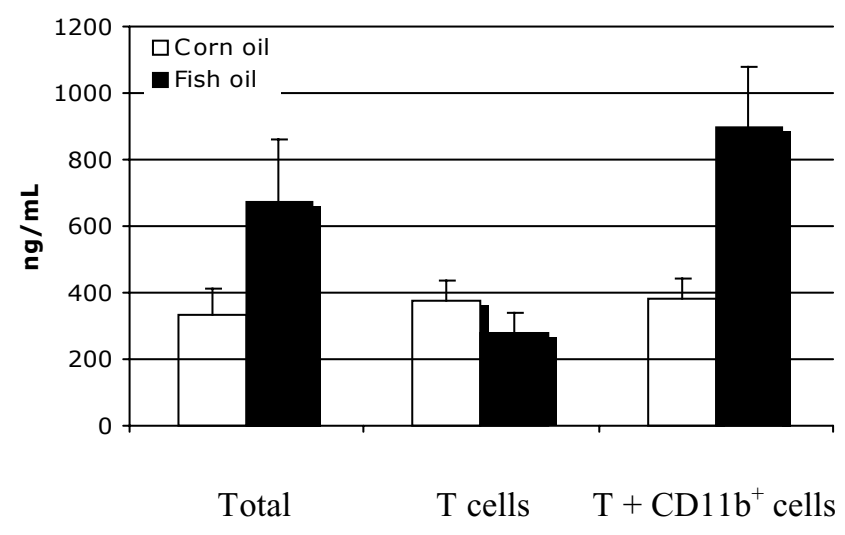

The results from the present study demonstrate that dietary fish oil directs the immune response of splenocytes towards a Th2 phenotype and that the effects of dietary fish oil on secretion of Th2 type cytokines are mediated by its effect on CD $11 b+$ accessory cells.

1. Calder PC (1997) Ann Nutr Metab 41, 203-234. 